\title{
O NEGÓCIO DA JUSTIÇA ELEITORAL: PROCESSO ELEITORAL
}

\author{
Gilberto Kilian dos Anjos ${ }^{1}$
}

\section{Introdução}

Em termos de reflexão acerca do planejamento estratégico, muito se debate no tocante à diretriz correta sobre o negócio da Justiça Eleitoral, ou seja, o norte de atuação primordial do trabalho dessa Justiça Especializada na sociedade contemporânea. De fato, algumas definições sobrelevam, tais como direitos políticos, processo eleitoral, soberania popular, regime democrático, dentre outras. No entanto, o estudo em tela objetivará a demonstração dos possíveis acertos e desacertos das descrições em apreço, como a síntese da atividade de uma Justiça que se preocupa, sobretudo, com uma clientela diferenciada: o eleitorado. Certo que, ao contrário do título do trabalho, não se quer estabelecer uma verdade absoluta, mas, sim, o estímulo ao pensamento quanto ao negócio da denominada Justiça Especializada. Vale dizer que o estudo aponta argumentos para se chegar à conclusão acerca da noção mais apropriada do negócio da Justiça Eleitoral.

\section{O conceito de negócio pela ótica do planejamento estratégico}

Em conformidade com o ensinamento de Nério Amboni (2006, mímeo): "Definir o negócio é explicar o âmbito de atuação/finalidade da organização". Com efeito, ainda na linha de caracterização da definição, Mauro Calixta Tavares (1991, p. 82) salienta que:

O negócio de uma organização define-se pelos desejos ou necessidades que ele satisfaz quando o usuário ou o consumidor compra seus produtos ou utiliza seus serviços, e não se deve ater à sua razão social, contratos ou estatutos.

Assim, o negócio de uma corporação não se confunde com os produtos ou serviços que ela oferece no mercado, mas, sim, traduz a aspiração que os clientes esperam como satisfação de seus próprios desejos e necessidades.

Dessa perspectiva, o negócio de uma corporação é pautado por dois planos que seguem unidos. De um lado, o plano externo, cujo significado 
se refere ao contentamento da clientela para além de uma dinâmica relacionada simplesmente na fruição dos produtos ou serviços de uma organização. Sob outra ótica, o plano interno, que cuida da situação do negócio no próprio âmbito da corporação, isto é, o alinhamento somado ao elemento valorativo que deve indicar o caminho para que haja o oferecimento do grau de excelência nos préstimos para a clientela. Tal distinção é bem demonstrada por Rui Otávio Bernardes de Andrade e Nério Amboni (2007, p. 3-5) quando estabelecem a diferença entre eficiência, eficácia e efetividade numa organização. Isso porque registram que a eficiência é uma medida de racionalidade entre custo/benefício, uma simples equação matemática em termos quantitativos. Já a eficácia é algo que excede, quer dizer, o grau racional quantitativo agregado ao diferencial qualitativo no que tange aos produtos ou serviços postos à disposição do mercado; em resumo, o alcance dos objetivos propostos pela empresa. Por derradeiro, quanto à efetividade, explicam que é ainda mais que a eficácia, pois corresponde à impressão que os produtos ou serviços causam na sociedade, o grau de satisfação social que a clientela tem ao usufruir o trabalho da corporação.

Por conseguinte, observa-se que o negócio resulta do amálgama dos dois planos e que em nenhum momento se pode confundi-lo com os serviços ou os produtos disponibilizados no mercado. Tanto é verdade que a corporação deve perseguir a perfeita sintonia entre os planos inerentes ao negócio para atingir a expressão do contentamento da clientela no consumo dos produtos ou serviços, somada à satisfação dos integrantes da corporação em oferecê-los no mercado. Em tal orientação, Nério Amboni (2006, mímeo) exemplifica que uma empresa de cascalho e asfalto poderia centrar o seu negócio em fabricar produtos relacionados a cascalho e asfalto. Todavia, dentro dessa visão simplista e míope, o autor lembra que, após alguma reflexão sobre a sua atuação no mercado, a empresa observaria que exerce um papel muito mais importante na sociedade do que apenas ofertar produtos de asfalto e cascalho. Realmente, fecha o ensinamento lecionando que, dentro de uma percepção mais aguçada, a empresa chegaria à conclusão de que oferece, no mercado, significativo benefício na vida das pessoas, na medida em que melhora a qualidade das construções realizadas pelo homem. Desse modo, numa visão estratégica, o negócio de uma corporação não se finda nos produtos ou serviços ofertados, decorrência do alcance de um olhar turvo do administrador, mas, sim, se relaciona à função social que esses mesmos produtos ou serviços exercem no mercado. Isto é, o grau de valor do contentamento da clientela acrescido da satisfação dos que compõem a empresa. Outras exemplificações poderiam ser salientadas. A loja que 
vende brinquedos não tem como negócio os produtos que oferta no mercado, e, sim, a alegria. A fábrica de cosméticos não detém como norte estratégico os produtos que oferece; diversamente, o seu negócio é a beleza.

Apresentado o substrato teórico acerca do negócio na representação do planejamento estratégico, tratar-se-á, no próximo tópico, das várias possibilidades de negócio para a Justiça Eleitoral, bem como se é possível lançar um negócio para a Administração Pública, tal qual utilizado para a iniciativa privada.

\section{Vários negócios para uma Justiça Eleitoral}

Apesar de não ter o negócio claramente explicitado, vê-se que, pela análise da missão, o Tribunal Superior Eleitoral infere que o seu negócio se encerra na manifestação da vontade da sociedade, por intermédio do direito de votar e de ser votado, traduzindo a caracterização de direitos políticos. Em sentido semelhante, pinçando o negócio da missão, o Tribunal Regional Eleitoral do Acre induz que o seu negócio é o exercício pleno dos direitos políticos. Por outro lado, pela análise da missão do Tribunal Regional Eleitoral de Goiás, deduz-se que o seu negócio seria a soberania popular. Também se poderia defender que o negócio de determinada Justiça Eleitoral, levando-se em conta o seu aspecto de abrangência, se pauta no regime democrático. Entretanto, com todo o respeito aos posicionamentos adotados, e considerando que os negócios foram devidamente extraídos das missões dos planejamentos estratégicos das esferas das respectivas Justiças Eleitorais, compreende-se que não alcançam toda a esfera do conceito de negócio da Justiça Eleitoral, ainda que não estejam incorretos, mas, talvez, na humilde opinião aqui perfilhada, sejam ou estreitos ou excessivos. Deveras, melhor analisálos isoladamente.

Como registra Manoel Jorge e Silva Neto (2008, p. 747), os direitos políticos são conceituados como "[...] os direitos fundamentais inerentes à participação do indivíduo na vida política do Estado". Diante dessa acepção, colhe-se na doutrina que os direitos políticos podem assumir um conceito restritivo ou extensivo. Na primeira noção, os direitos políticos se limitariam à capacidade eleitoral ativa e passiva, isto é, ao direito de votar e ser votado. Já na segunda idéia, os direitos políticos compreenderiam, além dessa pedra angular, o direito de ingressar com ação popular, a possibilidade de iniciativa popular, bem como a organização e participação de partidos políticos. Nesse sentido, Alexandre de Moraes (2008, 
p. 225-226) anota: "Podemos, igualmente, incluir como exercício da soberania e pertencente aos direitos políticos do cidadão: ajuizamento de ação popular e organização e participação de partidos políticos". Ora, em ambos os conceitos, tanto restritivo quanto extensivo, entende-se que os direitos políticos não cabem na concepção de negócio da Justiça Eleitoral. De um lado, na orientação restritiva, o atributo principal, direito de votar e ser votado, não é negócio da Justiça Especializada, porquanto quer parecer que nessa perspectiva o negócio é reduzido a uma visão simplista, não traduzindo a complexidade das atividades realizadas para a finalidade do pleito eleitoral. Por outro lado, no direcionamento extensivo, a Justiça Eleitoral não abrange a competência para a iniciativa popular e para a organização e participação de partidos políticos, concebendo-se na área interna corporis, muito embora, noutra quadra, o Supremo Tribunal Federal já tenha decidido pela jurisdição eleitoral para a ação popular, quando a matéria for pertinente ao ramo em comentário, apesar de a situação não ser muito habitual. Portanto, pedindo-se vênia aos que pensam em contrário, pontua-se não serem o negócio da Justiça Eleitoral os direitos políticos.

Quanto à soberania popular se caracterizar como negócio da Justiça Eleitoral, correto tecer alguns comentários. Conforme Maria Helena Diniz (1998, p. 388), o conceito de soberania do povo, ou popular, é: "SOBERANIA DO POVO. Ciência política. 1. Direito que tem o povo de autogovernarse, escolhendo os seus representantes, seus governantes e o governo. 2. Princípio segundo o qual todo o poder emana do povo, e em seu nome é exercido". Salienta-se, ainda, que a soberania popular é um dos pilares do regime democrático. Isso é muito claro se observado o ensinamento de José Afonso da Silva (2002, p. 131):

A democracia, em verdade, repousa sob dois princípios fundamentais ou primários, que Ihe dão a essência conceitual: a) o da soberania popular, segundo o qual o povo é a única fonte do poder, que se exprime pela regra de que todo o poder emana do povo; b) a participação, direta ou indireta, do povo no poder, para que este seja efetiva expressão da vontade popular; nos casos em que a participação é indireta, surge um princípio derivado ou secundário: o da representação.

Dessa forma, partindo da premissa de que é um dos princípios integrantes do regime democrático, a soberania popular não deve sintetizar o negócio da Justiça Eleitoral. Isso porque, com a parcela que lhe é cabível, a Justiça Eleitoral contribui para a garantia da soberania popular, bem como para que haja a concretização da expressão da vontade popular. No entanto, ainda que possa soar forte, acredita-se que a Justiça Eleito- 
ral não tem como proporcionar a soberania popular, no seu todo, em termos do conceito que se insere na democracia, por meio da realização das eleições. Então, verifica-se que um dos objetivos - não negócio - da Justiça Eleitoral é assegurar a soberania popular somada à garantia da participação do povo no poder, tanto na manifestação direta, quanto na indireta. Evidentemente, na medida de suas possibilidades e competência. Assim, não é o negócio da Justiça Eleitoral a soberania popular. É um dos seus objetivos. Ou seja, a Justiça Eleitoral persegue, como objetivo, a soberania popular, buscando concretizá-la no plano que lhe cabe por meio de instrumentos de participação política e consolidação da cidadania.

Deveras, a soberania popular é garantida por diversas outras formas. Para tanto, necessário observar outro fato que se atrela aos princípios do regime democrático: os valores. Anota-se, por oportuno, que os valores da democracia são a igualdade e a liberdade, na escorreita lição de José Afonso da Silva (2002, p. 131-132). Nesse sentido, os princípios deles não podem ser dissociados. Veja-se, assim, que a soberania popular, poder que é, revela-se conduzida pela igualdade e pela liberdade. Logo, como já dito, se reflete de várias maneiras. Para tornar mais convincente o argumento, nada melhor que a apresentação de exemplos: a) quando um juiz profere uma sentença, fazendo prevalecer a liberdade e a igualdade na interpretação da lei numa situação litigiosa, em última análise efetiva o regime democrático, que tem como um dos princípios a soberania popular; b) a soberania popular e, conseqüentemente, o regime democrático podem ser realizados pelas Forças Armadas quando algum cidadão queira tomar o poder de forma coativa, num verdadeiro golpe de Estado, $\mathrm{e}$ é impedido prontamente pelos militares; c) o Poder Legislativo também faz valer a sua contribuição para a soberania popular e, reflexamente, para a democracia, na proporção em que edita leis que estejam alinhadas com a igualdade e a liberdade.

Outras instituições trazem o seu fragmento contributivo para a soberania popular, e outros poderiam ser os exemplos, Ministério Público, imprensa, sociedade civil organizada. Entretanto, diga-se de passagem, nenhuma delas deve ter como negócio a soberania popular, porque todas oferecem a sua parcela, mas, salienta-se, nenhuma instituição pode assegurar isoladamente a soberania popular, independentemente do método utilizado. Destarte, as instituições até podem ter como objetivo a soberania popular, mas não tê-la como negócio, ou seja, nenhuma delas deve ter como negócio a soberania popular, porquanto todas ofertam a sua fração, porém, sublinha-se, nenhuma instituição pode garantir sepa- 
radamente a soberania popular, independentemente do modelo de atuação. Significa dizer que a soberania popular, poder que emana do povo, é construída pela convergência das forças das instituições para a formação do regime democrático.

Em tal aspecto, coloca-se a manifestação de Gaetano Silvestri, membro da Corte Costituzionale della Repubblica Italiana, que no artigo Sovranitá popolare e magistratura sintetiza o Estado como o modo ou o meio pelo qual se instrumentaliza constitucionalmente a soberania popular, por intermédio de suas mais variadas instituições, como, por exemplo, o Poder Judiciário, o Poder Executivo e o Poder Legislativo, ou seja, a soberania popular é fragmentada e defendida pelos inúmeros entes. Destaca-se o texto em comentário:

Nel costruire un modello giuridico di rapporti tra Stato e popolo, Vezio Crisafulli osserva, in uno dei suoi saggi più famosi, che la Costituzione italiana del 1948 introduce una vera e propria rappresentanza diretta del secondo da parte del primo, nel senso che lo Stato-soggetto agisce non soltanto per conto del popolo, ma anche nel suo nome.

'La cosiddetta contemplatio domini, ossia la dichiarazione espressa dell'agire per altri, che caratterizzerebbe la rappresentanza stricto sensu, si ritrova, infatti, nella disposizione della seconda parte dell'art. 1 (...). Dalla quale si ricava, precisamente, che la sovranità è e rimane del popolo, e che lo Stato soggetto è dunque soltanto una tra le 'forme' (rectius tra i mezzi) in cui essa viene costituzionalmente esercitata. Ciò che può considerarsi sufficiente a concretare il requisito della contemplatio domini, in linea generale, con riferimento, cioè, una volta per tutte, all'intera parte della potestà di governo il cui esercizio è demandato alla persona giuridica statale. Per talune manifestazioni, poi, della sovranità, esistono anche ulteriori più specifiche disposizioni, che ribadiscono tale requisito. Così, per la funzione giurisdizionale, l'art. 101, a termine del quale, 'la giustizia è amministrata in nome del popolo'; così, indirettamente, per la funzione legislativa, l'art. 67, sistematicamente inquadrato nel complesso delle disposizioni concernenti la formazione della legge (...). [V. CRISAFULLI, La sovranità popolare nella Costituzione italiana (note preliminari) (1954), ripubblicato in Stato popolo governo. Illusioni e delusioni costituzionali, Milano, 1985, p. 143]. Dalle parole di Crisafulli emerge una concezione rigorosamente giuridica del fondamento democratico dello Stato contemporaneo. Tutte le potestà statuali, esplicazioni delle diverse funzioni, emanano da un'unica fonte di legittimazione, al tempo stesso giuridica e politica, il popolo, che si avvale di una pluralità di 'mezzi' per esercitare costituzionalmente la propria sovranità. Le funzioni dello Stato non sono altro quindi che forme dell'esercizio della sovranità popolare. Quest'ultima non si coagula in un punto specifico, non si 
concentra in un soggetto determinato, ma risiede nel popolo, vale a dire nella comunità nazionale, ed acquista sembianza giuridica principalmente per il tramite dello Stato-soggetto nel sue diverse manifestazioni funzionali.

Na mesma direção, cabe salientar a lição de Friedrich Müller (2013, p. 56), ao ensinar acerca da legitimação do povo na esfera institucional estatal, conforme se observa adiante:

O povo ativo elege os seus representantes; do trabalho dos mesmos resultam (entre outras coisas) os textos das normas; estes são, por sua vez, implementados nas diferentes funções do aparelho de Estado; os destinatários, os atingidos por tais atos são potencialmente todos, a saber, o "povo" enquanto população. Tudo isso forma uma espécie de circulação de atos de legitimação, que em nenhum lugar pode ser interrompido (de modo não democrático). Esse é o lado democrático do que foi denominado estrutura de legitimação.

Portanto, ante os argumentos evidenciados, conclui-se que a soberania popular, muito embora seja um dos objetivos proeminentes da Justiça Eleitoral, não se lança como negócio dessa Justiça Especializada.

Por fim, em relação ao regime democrático caracterizar-se como negócio da Justiça Eleitoral, aponta-se que o conceito se ressente das mesmas problemáticas da idéia de soberania popular. Não é demais lembrar as palavras de Paulo Bonavides (2004, p. 18):

A mais incisiva e perfeita definição de democracia que a História moderna registra é, a nosso ver, aquela proveniente de Lincoln, o libertador de escravos, ao fazer-lhe o elogio, asseverando: "governo do povo, para o povo, pelo povo", "governo que jamais perecerá sobre a face da Terra".

Nessa esteira, o regime democrático também é um dos objetivos que a Justiça Eleitoral deseja alcançar, mas não é o seu negócio em si. É algo que a Justiça Eleitoral constrói com outras inúmeras instituições, pois pretender englobar o regime democrático como negócio da Justiça Especializada se demonstra utópico e apenas servirá como alinhamento puramente abstrato, tanto para os seus integrantes quanto para a sua clientela. Dessa maneira, resta que o regime democrático igualmente não é o negócio da Justiça Eleitoral.

\section{O negócio da Justiça Eleitoral: processo eleitoral}

Como foi delineado inicialmente neste trabalho, não se quer apresentar um conceito fechado de negócio para a Justiça Eleitoral, algo que seja 
revelado à semelhança de uma verdade absoluta. No entanto, na ordem do pensamento adotado, assinala-se que o negócio da Justiça Eleitoral é o processo eleitoral. Todavia, necessária a explicação do conceito para que haja a devida assimilação dessa idéia como negócio da mencionada Justiça Especializada.

Com efeito, o processo eleitoral deve ser entendido numa vertente formada por dois elementos indissociáveis, quais sejam, a fusão das eleições e da prestação jurisdicional. Realmente, as eleições se apresentam como todos os procedimentos necessários para preparação e execução dos pleitos eleitorais, desde o cadastramento eleitoral até a totalização dos resultados. Assim, as eleições não se confundem com produtos ou serviços isolados dispostos no mercado e utilizados pela clientela. Da mesma maneira, a prestação jurisdicional deve ser dimensionada na condição de todos os atos que conduzem ao real significado da expressão jurisdictio, que é dizer o direito. Por conseguinte, com todo o respeito às manifestações divergentes, já que o conceito chega a diversas definições conforme o ponto de partida, entende-se que o processo eleitoral é a noção que mais se amolda como negócio da Justiça Eleitoral, haja vista que é aquilo que definitivamente ela oferta para o mercado; é aquilo com que satisfaz a sua clientela. A rigor, ao propósito do estudo em tela, o negócio da Justiça Eleitoral é sintetizado pela seguinte fórmula: processo eleitoral = eleições + prestação jurisdicional.

Por outro prisma, poder-se-ia objetar, no que tange ao conceito exposto, notadamente devido à ausência de um valor, isto é, o anteriormente chamado contentamento da clientela no consumo dos produtos ou serviços adicionado à satisfação dos integrantes da instituição em prestálos ao mercado. Contudo, não há necessidade de que o contentamento e a satisfação, respectivamente, da clientela e dos colaboradores da instituição estejam no negócio, pois, no âmbito da Administração Pública, todos os benefícios são legais, diferentemente do que ocorre com a iniciativa privada. Na verdade, não existem benefícios fora do espírito da lei. Isso por uma razão muito simples: o Estado somente pode agir respaldado pela lei. Vem à memória o ensinamento de Hely Lopes Meirelles (2003, p. 102) sobre o significado do poder-dever:

Pouca ou nenhuma liberdade sobra ao administrador público para deixar de praticar atos de sua competência legal. Daí por que a omissão da autoridade ou o silêncio da Administração, quando deva agir ou manifestar-se, gera responsabilidade para o agente omisso e autoriza a obtenção do ato omitido por via judicial, notadamente por mandado de segurança, se lesivo de direito líquido e certo do interessado. 
Pode-se levantar qualquer espécie dos ditos benefícios - transparência, ética, celeridade, cortesia; todos, de uma forma ou de outra, são descritos pelas normas legais, seja pela caracterização de princípios jurídicos, como diretrizes que preenchem os denominados hard cases, seja pelo significado de regras, an all or nothing, na distinção estabelecida no pensamento de Ronald Dworkin (apud BONAVIDES, 2006, p. 281-282), Mestre de Harvard, sendo a Constituição a ordem balizadora.

Ademais, para finalizar, a nosso ver, é ousado fazer a junção ao processo eleitoral dos aqui chamados objetivos da Justiça Eleitoral como se fossem benefícios. Destarte, não se afigura como ideal destacar, como noção de negócio, a designação de processo eleitoral para o regime democrático, ou processo eleitoral para a soberania popular. Em primeiro lugar, esses complementos ao processo eleitoral são as expressões de alguns dos objetivos da Justiça Eleitoral e, também, apresentam-se como conceitos históricos e relativos, portanto não são benefícios. Discorrendo mais especificamente sobre a soberania, considerada em sua dimensão lato sensu, Paulo Bonavides (1986, p. 129-130) esclarece:

Considerável número de publicistas compreende nos dias presentes a soberania como um conceito histórico e relativo.

Histórico, porquanto a antigüidade o desconheceu em suas formas de organização política. Haja vista o exemplo da pólis grega, do Estado-cidade na Grécia clássica. A soberania surge apenas com o advento do Estado moderno, sem que nada por outra parte lhe assegure, de futuro, a continuidade.

Relativo, uma vez que tomado de início por elemento essencial do Estado - conforme sucedeu ainda entre juristas do século XIX - raro o autor hoje que após os trabalhos exaustivos de Jellinek ainda se ocupa da soberania sob o prisma do direito internacional, como de um dado essencial constitutivo do Estado. Há Estados soberanos e Estados não soberanos. Do ponto de vista externo, a soberania é apenas qualidade do poder, que a organização estatal poderá ostentar ou deixar de ostentar.

Do ponto de vista interno, porém, a soberania como conceito jurídico e social, se apresenta menos controvertida, visto que é da essência do ordenamento estatal uma superioridade e supremacia, a qual, resumindo já a noção de soberania, faz que o poder do Estado se sobreponha incontrastavelmente aos demais poderes sociais, que Ihes ficam subordinados.

Assim, conveniente deixar como negócio da Justiça Eleitoral o seu núcleo essencial, isto é, o processo eleitoral. 


\section{Considerações finais}

A título de considerações finais, algumas conclusões são pertinentes. A primeira de todas é que o negócio de uma instituição é aquilo que se define como a essência do que ela proporciona ao mercado, não se confundindo com os produtos ou serviços ofertados numa visão simplista e reducionista. Nessa perspectiva, o negócio da Justiça Eleitoral não deve ser algo que fica aquém do que ela realmente proporciona, nem pode estar além, fragmentado em diversas instituições, sob pena, nesse caso específico, de o negócio ser de todos e não ser de ninguém. Para tanto, observa-se que o negócio dessa Justiça Especializada deve ser o processo eleitoral, sintetizado no binário eleições e prestação jurisdicional, por ser efetivamente o núcleo essencial do trabalho que a Justiça Eleitoral oferece ao mercado.

Por sua vez, não há necessidade de agregar benefícios ao processo eleitoral, porquanto todos eles são legais, implícita ou explicitamente, diferente do que ocorre na iniciativa privada, onde uma corporação pode colocar como seu negócio a beleza ou a alegria. Nesse caso, é livre para definir o que bem entender, ainda que o seu negócio seja manifestamente utópico.

Por derradeiro, cumpre ressaltar que a junção do negócio processo eleitoral aos objetivos da Justiça Eleitoral, tais como, regime democrático e soberania popular, como se benefícios fossem, não se afigura como pertinente, porquanto além de se caracterizarem como objetivos, também são conceitos históricos e relativos, assim, definitivamente, não se enquadram na definição de benefícios. Portanto, no caso em concreto, não traduz relevância juntar eventual objetivo ao negócio, sob pena de confundir a essência da atividade da organização.

\section{Referências}

AMBONI, Nério. Base estratégica corporativa. Revista brasileira de administração. Brasília: ano XII, n. 37, p. 8-16, jun. 2002.

Planejamento estratégico empresarial. Florianópolis: 2006. (mímeo).

ANDRADE, Rui Otávio Bernardes de; AMBONI, Nério. Teoria geral da administração: das origens às perspectivas contemporâneas. São Paulo: MBooks, 2007.

BONAVIDES, Paulo. A Constituição aberta. 3. ed. São Paulo: Malheiros, 2004. 
Ciência política. 6. ed. Rio de Janeiro: Forense, 1986.

. Curso de Direito Constitucional. 19. ed. São Paulo: Malheiros, 2006.

DINIZ, Maria Helena. Dicionário jurídico. São Paulo: Saraiva, 1998. v. 4.

MEIRELLES, Hely Lopes. Direito Administrativo brasileiro. 28. ed. São Paulo: Malheiros, 2003.

MORAES, Alexandre de. Direito Constitucional. 23. ed. São Paulo: Atlas, 2008.

MÜLLER, Friedrich. Quem é o povo? 7. ed. São Paulo: Revista dos Tribunais, 2013.

SILVA, José Afonso da. Curso de Direito Constitucional positivo. 19. ed. São Paulo: Malheiros, 2002.

SILVA NETO, Manoel Jorge e. Curso de Direito Constitucional. 3. ed. Rio de Janeiro: Lumen Juris, 2008.

SILVESTRI, Gaetano. Sovranità popolare e magistratura. Disponível em: <http:/ /www.associazionedeicostituzionalisti.it/materiali/convegni/ 20030619_padova/doc/silvestri.doc>. Acesso em: 25 nov. 2008.

TAVARES, Mauro Calixta. Planejamento estratégico: a opção entre sucesso e fracasso empresarial. São Paulo: Harbra, 1991.

\section{Notas}

${ }^{1}$ Juiz Estadual do Tribunal de Justiça de Santa Catarina. 